\title{
25919 - EVALUATING TEAMWORK IN A SIMULATED OBSTETRICAL ENVIRONMENT
}

\section{Pamela Morgan MD, Richard Pittini, MD MEd; Glenn Regehr, PhD; Carol Marrs, ; Michele Haley, BA Sunnybrook And Women's College Health Sciences Centre, Toronto, ONTARIO, Canada}

INTRODUCTION: The National Confidential Enquiry into Maternal Deaths identified 'lack of communication and teamwork' as one of the leading causes of substandard obstetrical care. A recommendation of the National Steering Committee on Patient Safety in Canada was to create professional development curricula for multidisciplinary teams. We used high fidelity simulation to present obstetrical scenarios for feedback and team assessment.

METHODS: Obstetrical nurses, physicians, and residents in obstetrics and anesthesia were repeatedly assigned to teams of 5-6, each team managing 1 of 4 scenarios. Each person participated in 2-3 scenarios with differently constructed teams. Participants rated their team's performance using the Operating Room Management Attitudes Questionnaire (ORMAQ)1 and a global rating scale (GRS). Analyses of variance (ANOVA) were used to determine reliability of the two measures, and effects of both scenario and rater profession (RN vs. MD) on scores.

RESULTS: After REB approval, 16 nurses, 6 obstetricians, 6 anesthetists and 6 residents participated in 12 simulations, producing 71 ORMAQs and GRSs. The within-scenario 6rater reliability of team members' scores was 0.15 for the ORMAQ and 0.74 for the GRS. Inter-scenario reliability of team performance in the presence of specific individuals was zero for both measures, suggesting no systematically measurable effect of individuals on team performance. Analysis of variance revealed no significant difference between scenarios for ORMAQ scores $(\mathrm{F}<1$, ns), but a borderline difference for GRS ratings $(\mathrm{F}=2.92, \mathrm{p}<0.04)$, indicating the GRS identified some scenarios as more difficult than others. Analysis of scores by profession indicated that nurses gave significantly higher team scores than physicians on the ORMAQ ( $\mathrm{F}=6.26, \mathrm{p}<.05)$, but not on the GRS $(\mathrm{F}=2.96, \mathrm{~ns})$. An analysis of profession specific sub-scores on the ORMAQ revealed no interaction between profession of rater and profession being rated $(\mathrm{F}=1.98, \mathrm{~ns})$, suggesting both groups rated the two professions' performances similarly.

DISCUSSION: In this study the ORMAQ showed little or no ability to discriminate team performances. There was: a) no reliability either at the level of team or individual influences on the team, b) no discrimination among difficulty levels of the scenario, and c) some bias for nurses to rate all performances higher than physicians. However, the GRS rating showed moderate to good discrimination among team performances, some ability to discriminate difficult from easier scenarios and less bias in ratings by profession. Thus, with self-generated scores, the global rating appears to be performing better than the ORMAQ. Further work using ORMAQs from objective observers may discriminate performances but it may be necessary to develop a domain specific assessment tool for obstetrical team performance.

1. Bailliere's Clinical Anaesthesiology 1996;10:277-95 